\title{
Safety and Health in Schools
}

\author{
Huinee Voon, Tengku Mohammad Ariff
}

\begin{abstract}
Safety and health in a school is about employing a sensible and proportionate measure to identify and evaluate potential risks, and areas of weakness, capable of adversely affecting the school system. Objectives: To relate physical environment with safety and health in schools; and to study how risk assessments in schools can help in risk and hazard rectification. Methodology: A descriptive study, theoretical analysis. Results and discussion: A school-based risk assessment is one of the important approaches for improving safety and health conditions in schools. Therefore it has a significant role in protecting school employees and students against hazards in the physical environment. Conclusion: Although safety aspects are mainly emphasized in most schools, however, the health-related concerns that ensue from implementing those safety rules where workers' individual attributes in which human factors aspects should be taken into concern.
\end{abstract}

Index Terms:-Accidents, error, human factor, occupational.

\section{INTRODUCTION}

The physical environment of schools is one of the contributing factors to safety and health of the school and in the school psychosocial environment. Keeping school safe and secure involves an approach that includes deep insights about the school environment. Despite measures and procedures, and regulations implemented to address safety and security issues such as school access; emergencies; misuse of school properties and deliberate antisocial behaviours of students while on school grounds; incidents resulting in injuries and even death may still occur and are sometimes unexpected. In the meantime, schools can only control safety threats encountered by the school communities in or around the school compounds by the implementation of safety and security practices or procedures. However, since schools have a little amount of control over crimes that happened in the community and untoward incidents arising from the diverse group of people from different socioeconomic backgrounds, keeping schools out of safety and security threats is not always possible but not uncommon. School employees and students are exposed to a risk of violence and other safety related incidents that may occurred unexpectedly in schools. Thus, school facilities maintenance and school surveillance are some of the important aspects of a holistic approach to safety and security of a school due to reports of incidents of aggression and violence in schools.

Occupational safety and health (OSH) is concerned with protecting the safety, health and welfare of school employees, students, visitors, and clients. It covers the social, mental and physical well-being by dealing with both

Revised Manuscript Received on July 10, 2019.

Huinee Voon, Institute for Community (Health) Development (iCODE), Universiti Sultan Zainal Abidin, Terengganu, Malaysia.

Tengku Mohammad Ariff, Institute for Community (Health) Development (i-CODE), Universiti Sultan Zainal Abidin, Terengganu, Malaysia. safety and health in the workplace with the aim to reduce or minimise injury or disease, fatal or serious accidents, and to protect the health and wellbeing of school employees, students, visitors, and clients. In schools settings, this is strongly linked with everyday practise. Safety and health in a school is about employing a sensible and proportionate measure to ensure the facilities provide a safe and healthy place for all who utilise them. It helps to identify and evaluate potential risks, and areas of weakness, capable of adversely affecting the school system. As schools are workplaces too, they need to meet all occupational safety and health laws to keep its users safe. Educational facilities play a major role in the ability of school officials to respond to a variety of risks and hazards. They protect school employees, students and their family members, visitors, and any other people who come into contact with the schools. As students and teachers spend a large proportion of time in school buildings and on school grounds, and school premises are a valuable resource for the local communities to conduct activities and are increasingly being utilised for extended services, it is crucial that the school environments are as safe as possible. In educational facilities and outside school hours settings, safety and health practices tend to focus on the needs of students. Thus, additional safety and health threats that include the risk behaviour of students are examined in paper as well. Schools should be able to sustain a safe, secure, and healthy learning environment for all its occupants. OSH management in schools involves policies, guidelines, acts, legislation, and procedures that school need to comply. However, the schools' readiness and provision towards OSH may be somewhat known by looking at the official papers, protocols, and measures that the school have. Schools lacking in knowledge regarding the right procedures in execution of school activities may contribute to injuries and accidents among school employees, visitors, and clients. It may also put staffs in confusion in the appropriate procedure to apply and the right channels to complaint about work-related hazards. School management may also uninformed of the correct protocols to take when receiving OSH-related complaints among staffs.

Safety and health management in schools is crucial as it covers the moral, legal, and ethical reasons as hazards and risks exist in schools just like in other types of workplace. However, schools have a distinctive workplace settings as the school environment is also comprised of non-employees, or students which their number outweigh the number of employees. Countless cases of occupational related accidents and incidents are caused by a failure to implement the correct safety measures appropriately. The cost of occupational-related accidents can be exorbitant to both the

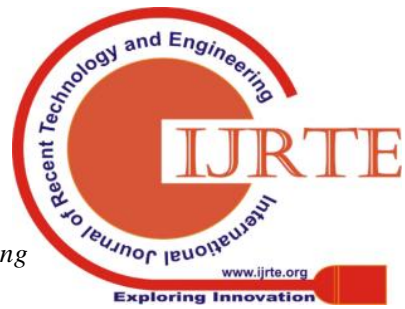


accident victim and employer. Some of the consequences employers have to face are recompensing sick pay, temporary replacement of sick workers, recruiting new employees or retraining workers; repairing damages inflicted on plant, equipment, materials, and products; allocating management time to deal with accidents; having an increase in insurance premiums or legal costs; and compensating claims made by accident victims or their family members. A preventive, change-oriented, and proactive safety and health management system promotes a safer working environment and helps in the prevention of accidents and incidents. An efficient, well-planned, and accessible safety and health management system gives teachers and staffs the confident when carrying out their duties or responsibilities. Financial priorities can be determined when conducting a cautious risk assessment procedure so that resources will not be wasted. In relation to that, school employee's absences as a result of occupationalrelated injuries or ill-health can be reduced and the probability and likelihood accidents and concomitant costs can be lowered. This can contribute to an improved morale in the school among staffs, students, parents or guardians. As the number of accidents and injuries decrease, the cost for paying compensation claims can be subsequently reduced.

Safety and health in schools is linked with everyday practice and the approach of employing a sensible and proportionate measure to ensure the facilities provide a safe and healthy place for all who utilise them. It helps to identify and evaluate potential risks, and areas of weakness, capable of adversely affecting the school system. As schools are workplaces too, they need to meet all occupational safety and health laws to keep its users safe. Educational facilities play a major role in the ability of school officials to respond to a variety of risks and hazards. They protect school employees, students and their family members, visitors, and any other people who come into contact with the schools. As students and teachers spend a large proportion of time in school buildings and on school grounds, and school premises are a valuable resource for the local communities to conduct activities and are increasingly being utilised for extended services, it is crucial that the school environments are as safe as possible. In elementary education and outside school hours settings, safety and health practices tend to focus on the needs of students. Thus, additional safety and health threats that include the aspects of human factors and human errors are discussed in the paper. Schools should be able to sustain a safe, secure, and healthy learning environment for all its occupants. Therefore, safety and health are of key importance to schools. In addition, instilling awareness at an early stage is of important to create a safe and healthy workplace in schools. The objectives of the paper is to relate the physical environment with psychosocial hazards in schools; and to study how risk assessments in schools can help in psychosocial risk and hazard rectification.

\section{MATERIALS AND METHODS}

This study was done using the qualitative research method. Document analysis was conducted where past studies and relevant documents are identified, interpreted and analysed to provide explanation and justification on the study objectives. Data were gathered from secondary sources which have consisted of academic journal papers, relevant books, magazines, periodicals, internet sources, web publications, and government releases. This approach was employed by reviewing preceding studies and available secondary resources in order to achieve the objectives of the study.

\section{RESULTS AND ANALYSIS}

\section{Objective 1: To relate physical environment with safety} and health in schools

The school environment can be described as the overall features of a school that can produce effective learning environment which made up of internal and external factors of school environments. The school's psychosocial environment describes factors that contribute to positive school climate and comprises the attitudes, feelings, values, and behaviours. It is associated with psychological safety, positive interpersonal relationships, recognition of the need and success of the individuals, and support for self-esteem development [1]. The psychosocial determinants to a safe and secure environment may include risk behaviours that can include elements of aggression and violence that can potentially influence self-esteem, encourage negative behaviours, and possibly affect the relationships and communication among the school community. In this sense, the physical school environment which provides school users with amenities that are safe, functioning, and wellmaintained is one of the determinants that can prevent the occurrence of accidents and injuries in schools; and to control the incidence of inappropriate behaviours that can negatively impact upon the school psychosocial environment. Therefore, when school is deemed a safe place by school users, an effective teaching and learning approaches can be created where the positive characteristics of the learning environment supports active learning process that offers the same opportunities and chances for participation. The school is a place where students spend a significant amount of their time at. Safety is more than just physical security and it is essential as it produces a sense of security in school that promotes learning and support

\section{A. Risk Behaviour and Schools}

Risk behaviour of students may be linked to physical characteristics of schools in which physical assessments of schools may help to identify and correct vulnerabilities. A safe and engaging school environment constructs the basis for encouraging academic, social, and emotional development among students. A review by [2] presented that fear of school crime can be attributed to individual and contextual risk factors, that include both the school and the neighbourhood. Overall, it is crucial for studies on schoolrelated crime to examine both individual and environmental factors to gain an insight of the ways in which fear is produced and persisted. The school environment may raise fear of crime by intensifying the possible risk for 
victimization [3]. High academic abilities are linked with reduce rates of risky behaviours and increased rates of health-related behaviours [4]. A safe and healthy school environment encourages student engagement [5] and protects against risky behaviors [6]-[8]. Health-risk behaviors are associated to lower grades and poor educational achievement [4]. Generally speaking, risk behaviours are most probable to multiply when individual risk factors are present in an environment that tolerates or supports risk behaviour. Risk behaviours typically begin throughout the schooling years and they are regularly noticed in the school settings. Schools embody the ideal place for health promotion that aims at adolescents as it provide the opportunity to reach a large number of audiences as students spent a significant amount of time in schools [9].

Injury is a major public health issue worldwide [10], [11]. Children and adolescents are the populations which injuries occur most [10]-[12]. Injury is the major cause of deaths among adolescents than other causes, and has the highest expenditure for health care services [13], [14]. Injuries can lead to disabilities, mental illness, and deaths among children and adolescents [15]. Previous researches conducted showed an increase concerns regarding adolescent injuries and related risk behaviours [15]-[17]. School spaces that are unmonitored seem to be 'hotspots' for a number of health-risk behaviours. For instance, violent behaviours and substance use were frequently identified with spaces like hallways, stairways, restrooms washrooms, changing-rooms and vacant classrooms. Based on a systematic review by [18], aggressive behaviour and substance use are frequently a strong indicator of status and bonding at schools where students feel academically marginalised or unsafe. Positive relationships with teachers seem to be crucial in encouraging student wellbeing and reducing risk behaviour. In spite of this, some areas of schools' organisation and education policies restrict this, increasing the probability that students search for a sense of identity and social support through health-risk behaviours. Unhappiness at school can lead students to look for ways of avoiding being in the school environment either by escaping school during lunchtime or for longer unauthorized periods or through substance use. These findings could be related to [19] theory of human functioning and school organisation, in which the study outcomes looking into the function of adolescents' or students' and their activities in establishing school environments and creating health risks.

Environmental cues associated to school problems have been linked with increased levels of fear. However, the effects of these environmental cues are not constrained to only the school context. The surrounding community incivilities and crime also interprets into fear of crime in or around schools [10], [20]. Being relentless due to the fear of victimization also has major impact on health [21].

Objective 2: To study how risk assessments in schools can help in psychosocial risk and hazard rectification

\section{B. Risk Management}

To ensure a safe and healthy work environment, it is important to identify potential safety or health risks within the school, and then eliminate or control those risks. The implementation of a risk management approach for maintaining the safety and health of persons in the schools was to ensure that: hazards that persons may be exposed to in the schools are identified; the risks, which is the likelihood and consequence of injury or harm to a person resulting from such hazards could be determine through the assessment conducted; the risks could be eliminate or reduce. If elimination is not feasible then the alternative possible mechanisms will be considered. A workplace risk assessment is a continual, on-going process or a basic investigation of what could possibly cause harm to people in the workplace and evaluation of whether adequate safety measures are applied or whether extra precautions should be implemented to prevent injury to persons at risk, employees and members of the public. Accidents and ill health can have undesirable impact on quality of life other than affecting businesses and organisations. Insurance costs or other financial penalties increase when output is lost and machinery is damaged. In many countries, employers are legally required to assess the risks in the workplace with the purpose of preparing a plan to control these risks.

\section{Risk Assessment in Schools}

The key features of safety and security involve the school's physical environment, security measures and safety and security policies that consist of procedural behavior aimed at responding to safety threats. Thus, this call for an approach that recognizes all aspects of creating safe environment in school that leaves no area for error and to address the gaps in the implementation of existing school safety and security measures through risk assessment can help to identify the security threats to a safe school environment. To create a holistic process, collaboration should be created with the local community as it is essential for improving school safety and security [22]. Involvement of students, teachers, parents, authorities, and nongovernmental organisations is important since safety threats at schools commonly akin to threats among the communities and hence the call for collaboration with community bodies, and allows room for community resources to be employed or utilized at schools such as assisting the school.

Initial action that helps to determine the current status of safety and security of the school should include a school environmental scanning process in which the current status of the school's physical and psychosocial environment are determined and gaps in security features and safety measures are identified. An active action and planning team or teams that comprise of school employees, parents, students, and community representatives should be established. Teams must have knowledge on the procedure carried out when examining the current status of the school's safety and security features and measures. Incidence reports, suspension or expulsions for violent behaviour, substance abuse statistics and weapon possession [22] may also be referred. This should be carried out according to the existing legislation concerning school safety and security best practices in school as highlighted 
and related to the physical environment aspects in schools. It then provides a database for weighing out and prioritizing decision.

A school-based risk assessment is one of the important approaches for improving safety and health conditions in schools. Therefore it has a significant role in protecting school employees and students against hazards, and at the same time complying with the laws and acts. It helps everyone centre on the risks that have potential to cause real harm the workplace, in this case, schools. International Labour Organisation [23] has introduced the general guidelines for employers, workers and their representatives on conducting workplace risk assessments. In many instances, direct measures that are simple, cheap, and effective can readily control risks in schools and ensure employees and students are protected. For example, guarded security access in at school gates, close-circuit televisions put in hidden areas of the schools, and procedures implement on the fetching and dropping of students at schools. The key to undertaking risk assessments in schools is not to complicate the process. Like most organisations, the risks in schools may already well known and the required control measures are easy to apply. Those involved in carrying out the risk assessment probably already know whether, for instance, the time which additional securities should be stationed at school gates, or the spots in schools where students are most likely to held suspicious meetings. Subsequently, schools should check that reasonable precautions are in place to avoid safety and security triggers that could results in injury and ill health. School authorities may collaborate with employees and and/or their representatives when undertaking the risk assessment providing that they are confident and understand what is going on. Above all, school employers must make sure that employees and/or their representatives participate in the process actively. They should have useful information about how the work is done that will ensure the risk assessment will be conducted in a systematic manner and is effective afterwards. But school authorities should bear in mind that employers are the one who will be responsible for seeing that the assessment is conducted properly.

When conducting the risk assessment, schools should remember that a hazard is anything that may cause harm, for examples, chemicals, sharp objects, walking on the parking lot, crossing the streets etc.; and risk is the chance that someone could be harmed by these and other hazards, together with the levels of how serious the harm could be. A well conducted school based risk assessment will contribute to the protection of school employees and students by eliminating or minimizing safety related hazards and risks and consequently improving the level of security in schools. It should also benefit schools through better organisation of working practices potentially increasing safety and security aspects in the schools. The methodology described in article is not the only way to conduct risk assessments, perhaps there are other methods that can address the safety and security issues in schools better and more appropriate to the type of risks and circumstances faced by the schools. However, this method is the most straightforward approach for assessing the safety and security levels in schools.

\section{Identify the Hazards}

The first step to risk assessment is to identify the hazards where schools need to identify out how the security of school employees, students, and visitors could be harm. This is done by surveying the school premises and identifying the probable hazards as an unidentified hazard cannot be controlled. It is not uncommon to overlook some hazards that are present in the workplace and hazards may not be apparently obvious as human eventually got used to the same environment or settings every day. A walkthrough analysis may be done where assessors can walk around the school premises and observe what could possibly be expected to cause harm. All regular and irregular activities within or near the schools compound should be addressed and the assessment must covers the entire school. Employees or representatives should be aware of the hazards safety presented and deliver information as to how accidents can be prevented and security levels can be raise. Schools can learn from previous examples in which security has been breached in schools and may help to identify the less evident hazards. The Therefore, school safety and security are important and interconnected with the school psychosocial environment and the wellbeing of students. The purpose of hazard identification is to highlight hazards that posed significant risks to the safety and health to school users. In this stage, the situations and things that could cause death, injury, or illness were identified. Hazards concerning to certain equipment, working circumstances or activities performed were identified. Hazards commonly arise from interaction with the physical working environment; the way of performing work activities; equipment, materials and substances used; work design and management; and individual's behaviour at work. Hazards can be divided into five main categories; biological hazards, chemical hazards, physical hazards, ergonomics hazards, and psychosocial hazards.

Biological hazards can be resultant from working with animals, people, or infectious plant materials. School workplaces and activities such as laboratories, canteens, outdoor excursions, etc. may expose a person to biological hazards like blood or other body fluids; fungi/ mould; bacteria and viruses; plants; insect bites; and animal droppings. Chemical hazards can be avoided in which school physical interiors should be cleaned daily and major cleaning can be carried out in semester breaks. The use of chemical products with hazardous side effects to health should be avoided when cleaning school buildings. The risk of toxic chemical exposure and damage occurs when the hazard is not known or recognized and the correct precautions and training have not been used for the handling/storage of hazardous substances. Chemicals at schools can range from cleaning products to chemical production. Chemicals can cause injury, illness, fire or even explosions at the extreme when there is no proper handling or storage of chemicals, even if it is not in use. Chemical hazards expose a person to risk through skin contact, inhalation, and ingestion. The affect can takes place 
immediately or after a period of prolonged exposure. Hazards may be also found in unlabeled container of acids, vapours and fumes produce from welding works; gases such as acetylene, propane, carbon monoxide and helium; flammable materials like gasoline, solvents, and explosive chemicals; and pesticides. Physical hazards cause injury, illness and death through and commonly found in substances or activities that threaten one's physical safety. Some of the common physical hazards are extreme temperature; contaminated air; mould; constant noise or radiation; and high exposure to sunlight/ultraviolet rays. The right equipment, monitoring and training should be provided; and employees should have an effective communication in the schools. Ergonomic hazards may be caused by improperly adjusted workstations and chairs that frequent lifting, poor posture, awkward and repetitive movements, frequent use of force exertions, and vibration. They may causes injuries or strains from lifting, pushing, or pulling; standing; or slips and falls. Psychosocial hazards includes stress, violence, bullying, excessive workload, intensity and pace, lack of respect, flexibility, control, social support or relations, and sexual harassment in the workplace environment. Emotional responses that arise from the interaction within the working environment can subsequently affect person's productivity or effectiveness. Resources or mediums should be available for school occupants to convey concerns related to psychosocial hazards such as regular meetings on a one-on-one basis where employees or students can voice out their concerns.

\section{Identify Who Might be Harmed and How}

In the second step, the people that might be harmed and how they could be harmed by the hazard is identified. This will help in determining the best measure of managing the risk such as what type of injury or ill health that might have occurred. Some employees and students have particular requirements. For instance, lone working in some areas of the schools, newly registered elementary school students, or students with disabilities may be at particular risk. Additional measures for some hazards may reduce the risk of school members being exposed to harm. Schools should also be alert of outsiders or unknown people gaining access into the school compound as strangers may easily pose as cleaners, visitors, contractors, and maintenance workers. Individuals working on these jobs in schools may not be in the school all the time and schools should take appropriate measures in ensuring that there are no mistaken identities of outsiders camouflaging as workers in schools. In addition, schools should be able to implement the correct procedures of parents picking up kids from school during school hours and the time which parents are not allowed to be in the school compounds to avoid people taking advantage of the recess time for entering into school premises. Schools should also lay out the precautions in dealing with violence or aggression among students against teachers, staff members, and other students. Schools should also be alert of wary people that gather near the school premises that could trigger violence and aggression in the schools.

\section{Risk Assessment}

Risk assessment is the approach to determine the risk level associated with a particular hazard. The risk rating can be used to prioritise subsequent risk control measures and actions. In this phase, it is vital to recognize the characteristics of risks that could be created by a particular hazard, the consequences or severity it induces and the likelihood of it occurring. When establishing the level of risk, the experience of the person who encountered the hazard; the rate and/or time of the individual's contact with the hazard; any current controls; causal environmental factors; and pre-existing hazards should be taken into consideration.

\section{Risk Evaluation}

After the hazards have been identified, decisions are then made to in dealing with the hazards. The safety and health risk control measures will be identified and decided on. This can be achieved by comparing what is being done with good practice in the schools by looking at the available controls and how work is organized. Assessors can then do a comparison with good practice and see whether there are additional efforts that could be done to increase the security in the schools. Aspects that should be considered are whether the hazards can be removed completely. For example, eliminate the hazard by removing thick bushy shrubs. When controlling risks, the following hierarchy of controls should be considered if possible so that harm is unlikely to occur. Sschools can select a less risky alternative such as using a less hazardous chemical; substitution of the hazard; and distribute personal protective equipment such as eyewear, gloves, and aprons to the students. Improving safety and health does not necessarily require a huge cost. Failure to take simple precautions can cost schools and school users financially and ill health resulting from accidents or injuries. Employers and employees carrying out the assessments in a team will help to make certain that any recommended risk control measures will be effective after being put in place and new hazards would not be brought in All employees in the school must be trained in the new control measures implemented to make sure that they are used or utilized appropriately. The hazards identified are then evaluated to determine the subsequent actions that need to be performed; it requires employers to do everything possible to protect people from harm. The existing controls should be re-examine and how the safety procedure are organised to improve the level of security in the schools. Risks in schools can be approach using the hierarchy of controls which involves the use of PPE, Administrative, Engineering, Substitution, and Elimination method.

A control strategy to either eliminate or reduce the risk is developed after the hazards and the possible risks have been identified. Each OSH hazard that has been identified will be then eliminate or reduce by applying the principles of the hierarchy of control. Control strategies must be studied in the order of the hierarchy shown below to enable schools to apply the most effective control strategy that are reasonably 
feasible in the situations. Deciding on an appropriate control includes evaluating and choosing temporary and permanent controls; the applying of short-term measures to protect school users until fixed controls can be applied; and suggesting long term controls when reasonably feasible. Yet, not all control methods that is solely implemented will decrease the residual risk to an acceptable or tolerable level. In such conditions, the implementation of two or more risk controls in combination to reach the ideal risk reduction should be considered. The control method represented in the figure below is recommended to ascertain the effectiveness of control strategies.

Once hazards have been identified, a control strategy to either eliminate or control the risk is to be developed and implemented. In elimination, the hazard is completely removed. A hazardous job, tool, process, machine or substance is removed to protect members of the school. For example, removals of hazardous liquids such as bleach from places that could be easily access by anyone. If the hazard is eliminated, the level of risk is eliminated. Substitution is where changes are introduced into a work practice, substance or piece of equipment to provide a safer environment. Hazardous materials or substances are substituted for less hazardous substances. Controls should be able to protect school occupants from security hazards. In and/or environmental conditions is modified. The approach of redesign, isolation, automation; and the use of barriers, absorption, and dilution methods are applied. For example, the use of barbed fences around the school premises. In administrative approach, work procedures and methods to control the interaction between people and hazards are developed to minimise exposure to a hazard. This may include the design of safe work procedures; supervision; and education and training; housekeeping, repair, and maintenance programs; signage; labelling; policies, rules, and hygiene. For examples, procedures for visitors entering the school, using warning signs to warn school users of a hazard, or limiting exposure time to a hazard (kids should only wait in the school compound after a certain period of time when waiting to be fetched after the school hours) so they are better able to identify/report/control/avoid hazards in the workplace. School employees, teachers and students must also be trained in usage of Personal Protective Equipment and understand the limitations of those equipments.

In this stage, the actual action planning for enhancing safety and security at the schools is carried out. It is designed at securing the school, promote safety and promote a safe school environment. The action plan involves setting objectives for improvement and prioritizing areas that need to be addressed immediately and those that have to be addressed in the long-term. Past incidences, reports, and current statistics related to safety threats are crucial for prioritization of security hazards that need to be treated at this stage of planning. Goals are meant to be achievable and measurable to ensure that implementation can be executed and be monitored regularly. The best method of conducting an action plan is to ensure that inputs are collected from various school stakeholders. Prior to recommending risk controls, it should always be remembered that no new and engineering approach, the design of the workplace or plant

seemingly unrelated hazards will be created, in which this could be done by reviewing the proposed recommendations. For example, fixing barricades or fixtures on facilities can restrict access and means of escape. A single control will normally influence the likelihood or consequence of the threat occurring. Any latest update of relevant administrative controls concerning hazards should be sought from the schools. For examples, the addition or the purchased of new equipment, the existing workplace inspection checklists, and/ or safe work procedures were considered in the assessment.

\section{Documentation of Risk Control Measures and the Timeframe}

If extra controls actions have been suggested and decided, the next action should be taken to ensure they are implemented in the schools. In this step, responsibilities are assigned to named individuals, in addition to the time frame allocated for implementation. The date of the implementation should also be recorded. Acting on the findings of the risk assessment is crucial in eliminating or minimizing safety and security related hazards and risks. New control measures may be required but schools may not have all the necessary resources to implement all at the same time. Some additional control measures can be implemented immediately with limited resource such as providing adequate supervision and security procedures etc. However, others will have to be prioritized based on the level of risk it exposes to school users. An action plan for managing the risks should include a combination of a number of considerations, for example: a number of inexpensive or straightforward measures that can be carried out immediately as short-term solutions until new reliable controls are implemented; long-term solutions to risks that are most likely to cause accidents or ill health; or with the worst potential consequences; arrangements for training workers on the high residual risk and how they should be controlled; regular checks to ensure that the control measures remain in place.

\section{Documentation of Findings, Monitor, and Review}

The final step in the process is to review the risk controls that have been recommended after the risk assessment has been carried out. Consultation with the schools and feedback received will provide information on the application of risk controls at the school workplace level. The assessors and school management OSH nominee should to determine if the risk controls are feasible and effective in reducing the residual risk rating to a tolerable level. There will be a need for communication across the school community and the involved parties throughout this process. This requires continuous monitoring and evaluation of the effectiveness of measures that have been put in place. As there will be more direct smaller and specific plans that address certain issues and areas of safety and security, continuous monitoring and evaluation is key to ensure that an implementation is carried out accordingly and the effectiveness of the implementation is evaluated. Therefore,

Blue Eyes Intelligence Engineering 
documentation, records, and feedbacks of implementation, monitoring, and evaluation process are necessary to keep track of the effectiveness of the safety measures. In order to implemented, some workplace inspection arrangements would be necessary. Assessors may identify in step 3 the must to carry out daily/weekly/ monthly workplace inspections as one of the necessary control measures. Workplaces may not remain the same as new equipment, substances, and procedures may be introduced and placed in and this could cause in new hazards being created. As for that reason, review is conducted on a continuously to formally evaluate whether the assessment is still valid. This will help to check whether occupational safety and health standards are improving, or at least not worsen. Assessors should examine the risk assessment again and see whether there should be any changes after the measures have been introduced and additional controls are still required for improvement. Also, other or new identified issues, or weaknesses in occupational safety and health management identified in accident or near miss investigations should be considered in the review. To sum up, the risk assessment should always stays up to date. If there is a significant change during the year, the risk assessment should be check immediately and, if needed, revise it. It is best to review the risk assessment when there are changes in planning. This helps to make sure that new hazards are not brought in and suitable control measures are in place [23].

\section{DISCUSSION}

Emotional and physical safety is defined as the freedom from actual and perceived emotional or physical harm. Actual and perceived safety in the school environment enable and help students to pay attention continuously enables analytical reasoning and effective communication during the learning process. Safety in schools can contribute to better academic performance and lowered the number of incidents related to violence and aggression. On the contrary, students' self-confidence, motivation, commitment, attendance, and grades are negatively affected when they feel unsafe in school [24]. Creating a safe and secure school environment involves a holistic approach or implementation of measures that not only addresses negative risk behaviours such as violence and bullying, but also the built environment of the infrastructure which may encourages the likehood of these events from occurring. Addressing the physical environment of the school lays the foundation for dealing with psychosocial threats that usually take place in schools. Thus, it is imperative to take in a balanced view of the school safety and security with regards to the physical and psychosocial environment. Focus in applying school safety and security measures may calls for the need of a holistic approach from all stakeholders, which it may requires a continuous monitoring and evaluation feedback that facilitates the process of planning and improvement. Schools should be an environment that helps students to develop and achieve the maximum potential of their abilities. The role of schools as academic institutions that promote healthy environments may support students' academic, social, and emotional growth [25]. Further studies of this relationship would increase the understanding of monitor the effectiveness of the control measures

those associations and experiences within schools. It needs an overall approach of all relevant physical attributes or areas of the school's built environment in the socialization processes. Approaches to investigate the influence of the built environment and student outcomes mostly emphasize on one particular physical parameter in the school environment without wider effect on students' overall experience in the schools. Efforts to align the design of the built environment will help to form a positive, safe, and secure environment for students' social and emotional academic development. This will require relevant stakeholders, policy makers, all relevant parties to implement a holistic approach. For instance, being safe in areas in the schools susceptible safety and security issues and student misbehaviours [26].

\section{CONCLUSION}

An analysis of the safety and health hazards in the schools is crucial to the practice of planning, management and the operation of an organisation. Positive changes in the school working environment by which substandard act and working condition are recognised before corrective actions are developed and implemented. Recommendations on risk and hazard control measures should be suggested based on the utilisation of several resources when implementing, maintaining, and reviewing OSH risk and hazard control measures in the schools in order to be effective. OSH hazards are routinely identified by conducting a consultation with relevant persons from the schools, including reviewing existing OSH hazards and, new hazards that may be presented when work practices, circumstances, or premises changed. However, the human factors and human error in perceiving hazards may reduce the overall effectiveness of a particular safety measure.

\section{REFERENCES}

1. International Labour Organization (ILO), A 5 step guide for employers, workers and their representatives on conducting workplace risk assessments. 2013, Available: http://www.ilo.org/safework/info/publications/WCMS_23288 6/lang--en/index.htm.

2. K. Swartz, B. W. Reyns, B. Henson, and P. Wilcox, "Fear of in-school victimization: Contextual, gendered, and developmental considerations," Youth Violence and Juvenile Justice, 9(1), 2011, pp. 59-78.

3. C. J. Schreck, and J. M. Miller, "Sources of fear of crime at school: What is the relative contribution of disorder, individual characteristics, and school security?" Journal of School Violence, 2(4), 2003, pp. 57-79.

4. Centers for Disease Control and Prevention (CDC), Health and Academic Achievement Overview. Georgia: National Center for Chronic Disease Prevention and Health Promotion, 2014.

5. R.W. Blum, C. McNeely, and J. Nonnemaker, "Vulnerability, risk, and protection," Journal of Adolescent Health, 31(1), 2002, pp. 28-39.

6. D. E. Bontempo, and A. R. d'Augelli, "Effects of at-school victimization and sexual orientation on lesbian, gay, or bisexual youths' health risk behavior," Journal of Adolescent Health, 30(5), 2002, pp. 364-374 
7. M. Henderson, R. Ecob, D. Wight, and C. Abraham, "What explains between-school differences in rates of smoking?" BMC Public Health, 8(1), 2008, pp. 1-16.

8. P. Aveyard, W. A. Markham, E. Lancashire, A. Bullock, C. Macarthur, K. K. Cheng, and H. Daniels, "The influence of school culture on smoking among pupils," Social Science and Medicine, 58(9), 2004, pp. 1767-1780.

9. D. Rovis, H. Jonkman, and J. Basic, "A multilevel analysis of adverse family relations, school bonding and risk behaviours among adolescents," Journal of Child and Family Studies, 25(2), 2016, pp. 647-660.

10. D. C. May, and R. G. Dunaway, "Predictors of fear of criminal victimization at school among adolescents," Sociological Spectrum, 20(2), 2000, pp. 149-168.

11. S. M. Wang, and K. Dalal, "Safe communities in China as a strategy for injury prevention and safety promotion programmes in the era of rapid economic growth," Journal of Community Health, 38(1), 2013, pp. 205-214.

12. C. Mock, R. Quansah, R. Krishnan, C. A. Risa, and F. Rivara, "Strengthening the prevention and care of injuries worldwide," The Lancet, 363(9427), 2004, pp. 2172-2179.

13. C. Ji, and F. Tao, "The prevention of unintentional injury among children and adolescents," China Journal of Public Health, 21(9), 2005, pp. 1150-1152.

14. Y. Zhou, D. Timothy. Baker, R. Keqin, and L. Guohua, "Productivity losses from injury in China," Injury Prevention, 9(2), 2003, pp. 124-127.

15. C. F. Li, C. Y. Li, and C. M. Zhang, "Study on unintentional injury and intervention strategies for child and adolescent," Maternal Child Health Care China, 23, 2008, pp. 3260-3261.

16. D. A. Sleet, M. F. Ballesteros, and N. N. Borse, "A review of unintentional injuries in adolescents," Annual Review of Public Health, 31, 2010, pp. 195-212.

17. S. M. Wang, Community Injury Prevention and Safety Promotion-Theory and Practice. Shanghai: Fudan Publishing House, 2010.

18. F. Jamal, A. Fletcher, A. Harden, H. Wells, J. Thomas, and C. Bonell, "The school environment and student health: A systematic review and meta-ethnography of qualitative research," BMC Public Health, 13(1), 2013, pp. 1-11.

19. W. A. Markham, and P. Aveyard, "A new theory of health promoting schools based on human functioning, school organisation and pedagogic practice," Social Science and Medicine, 56(6), 2003, pp. 1209-1220.

20. J. McDevitt, and J. Panniello, National Assessment of School Resource Officer Programs: Survey of Students in Three Large New SRO Programs. Document Number 209270, Washington DC: US Department of Justice, 2005.

21. R. Lawrence, School Crime and Juvenile Justice. New York: Oxford University Press, 2007.

22. I. Pollack, and C. Sundermann, "Creating safe schools: A comprehensive approach,” Juvenile Justice, 8(13), 2001, pp. 13.

23. International Labour Organisation, Home. 2013, https://www.ilo.org/global/lang--en/index.htm.

24. S. E. Goldstein, A. Young, and C, Boyd, "Relational aggression at school: Associations with school safety and social climate," Journal of Youth and Adolescence, 37(6), 2008, pp. 641-654.

25. Z. J. Cao, Y. Chen, and S. M. Wang, "Health belief model based evaluation of school health education programme for injury prevention among high school students in the community context," BMC Public Health, 14(1), 2014, pp. 18.

26. M. Garibaldi, and L. Josias, "Designing schools to support socialization processes of students," Procedia Manufacturing, 3, 2015, pp. 1587-1594. 